science. Much needs to be done to improve the analysis of porsonnel policies and practices; the personnel officer needs fuller understanding of and participation in oporational research and management studies to solve his own problems more effectively, and to contribute more positively to planning and decision-making, to administration and management in tho enterprise as $a$ whole.

T. H. HawkINS

\title{
PREPARATION AND STANDARDIZATION OF ISOTOPIC TARGETS AND FOILS
}

\begin{abstract}
CTABLE and radioactivo isotopic films and foils of $\$$ precise composition and dimonsions are needed as targets for a variety of particle accelerators for nuclear data measurements; accurately defined films of $\alpha$-active actinides are also ne日ded as fission standards for reactors. Such standard targets are made in a number of laboratories in different countries and there was a clear need for closer co-ordination with the usors in order to relate the limits of chemical purity and dimensional tolerance desirable to those practically attainable. To meet this need and also to promote an interchange of ideas and techniques a seminar was held at Harwell, Didcot, during October 20-21, 1965. The hosts were the Electromagnetic Separation Group of the Atomic Energy Research Establishmont (A.E.R.E.) and the Special Tochniques Section of the Nuclear Physics Division of the Atomic Weapons Research Establishment (A.W.R.E.).
\end{abstract}

Tho seminar, of about seventy scientists, was strongly supported by the Central Bureau of Nuclear Measuremonts of Euratom, Geel, Belgium, and the isotopic Target Preparation Centre of O̊k Ridge National Laboratory (O.R.N.L.), Tennessee. Participants from laboratories in eight other countries also contributed to the 30 papers and the discussions.

Isotopic targets, which may be required on backings or self-supported, generally range in thickness from a few $\mu \mathrm{g} / \mathrm{cm}^{2}$ to several $\mathrm{mg} / \mathrm{cm}^{2}$. A wide variety of chomical techniques such as vacuum ovaporation, electrodeposition and electrospraying, and metallurgical methods are used, but probloms arise owing to the small amounts of expensive isotopic material availablo, the risks of isotopic contamination and the need for high chemical purity and exactly known thicknesses. Chemical conversions and purifications on the sub-gram scalo may have to precede the target-making process.

During the first day the meeting considered the problems involved in these methods, means of improving process efficiencies and the effects of impurities. G. H. Debus of the Geel Laboratory emphasized the difficulties involved in obtaining exact and realistic specifications from users, in preparing and transporting samples, and obtaining from users adequate comments on tho bohaviour of the targets which would help future preparations. Other contributions from the Geel Laboratory discussed non-uniformity of doposits and isotopic fractionation during evaporation. G. T. Arnison of A.W.R.E. analysed the experience gained using electron bombardment techniques instead of rosistanco heating for vacuum ovaporation. The description by W. Parker of the Chalmers University of Technology, Gothenburg, of the novel method of "molecular plating' from organic solutions, which appears especially useful for making actinide targets, excited much interost. Experience with established methods for making $\alpha$-active sources was reviewed by Mrs. Glover of A.E.R.E. and J. Champion of the French Atomic Energy Commission.

For many applications unbacked targets are desired, and several laboratories use metallurgical techniques to make isotopic metallic foils of thickness down to below $1 \mathrm{mg} / \mathrm{cm}^{2}$. The end-product of electromagnetic isotope separation is normally the oxide, and methods of efficiently converting small quantities of the valuable isotopes to the metal were described. A range of foils of the isotopes of the rare earth metals, reactive alkaline earth metals and some of the actinides has been prepared by simultaneous reduction-distillation followed by rolling or evaporation at O.R.N.L. Some of these were shown by E. H. Kobisk, who also considered the merits of ultra-high vacuum techniques as a means of obtaining high purities. The techniques used at the Argonne National Laboratory for rolling films down to thicknesses of a few microns and at Geel for high-froquency levitation molting and evaporation were described. This latter method avoids contamination by crucible material and can be used for metallic samples of 3-100 mg. J. B. Reynolds of A.E.R.E. listed the thin stablo isotope metallic foils now made at Harwell by rolling techniques and showed how the deformities and thickness contours in a rolled foil had been measured by attenuation of $5-\mathrm{MeV} \alpha$-particlos. The problems of preparing targets by very small-scale electroplating were discussod by several speakers.

The second half of the meeting was concerned with measurement and standardization. F. A. Howe, A.W.R.E., introduced the topic with a critical survey of the nondestructive methods for determination of film thickness which were applicable to nuclear targets. Mothods used at Geel for precise standardization of the chemical and physical properties of targets were reviewed by $\mathrm{H}$. Moret and K. F. Lauer and some specific procedures were described by other speakers. This aspect of thin-film preparation will undoubtedly receive increased attention in the future, and the first seminar on the subject was particularly useful in making the participants aware of the many causes of errors which can exist in the determination of purity, uniformity and thickness of isotopic targets. Both makers and users will undoubtedly be more cautious in the future and will understand oach other's problems better. More efforts will be made to introduce monitors to follow the continuous build-up of targets and to control and measure the chemical and physical characteristics of the films and foils.

Copies of the sominar programme and abstracts and, later, the record of the proceedings can be obtained from the following address: Electromagnetic Separation Group, Atomic Energy Roscarch Establishment, Harwell, Didcot, Berkshire.
M. L. SмMT̄in

\section{THE NATIONAL INSTITUTE OF OCEANOGRAPHY}

THE National Oceanographic Council met for the last time on October 20,1965 , and decided to petition the Queen to withdraw the Royal Charter granted in 1950. This was the final stage of the chango-over of the responsibility for the National Institute of Oceanography from tho
National Oceanographic Council to the recently formed Natural Environment Research Council. Mr. J, P. W. Mallalieu, Parliamentary Under-Secretary of State for the Royal Navy and chairman of the National Oceanographic Council, while thanking the Council for their work over 
the past 15 years in promoting the study of oceanography in Britain, reforred to the growing public recognition of the importance of oceanography.

During the Second World War, very much as a consequence of the remarkable work on waves carried out by Dr. Deacon's group at the Admiralty Research Laboratory at Teddington, it was felt by many people that there should be a more concerted attack in Britain on research iato the physies of the sea, and eventually, in 1949, after discussion between the Advisory Council on Scientific Policy and various Government departments the National Institute of Oceanography came into being with Dr. G. E. R. Deacon as director-the Royal Charter being granted to the National Oceanographic Council in the following year. The whole schome provided for: (1) A Royal Charter incorporating a National Oceanographic Council with the object of advancing the science of oceanography in all its aspects, under the chairmanship of the Civil Lord of the Admiralty, and consisting of representatives of Government departments, tho learned societies, the universities and those Governments of the Commonwealth that might be expected to give financial support. (2) An executive committee to implement the policy of the Council. (3) A National Institute of Oceanography to carry out the work of the Council.

Over the past 16 yoars the money has been provided more or less in equal proportion by the Development Commission and by the Admiralty, and there have been welcome but relatively small contributions from various Commonwealth countries. The income in $1949-50$ was just over $£ 100,000$, in $1963-64$ some $£ 400,000$. The nucleus for the investigation of the physics of the sea was Dr. Deacon's wave group; the nucleus of the biology departmont was the long-existing Discovery Investigations.

The National Oceanographic Council held its final meeting at the National Institute of Oceanography in Wormley, Surrey, and the occasion was marked by a display of exhibits illustrating the work. A press conference was held, chaired by Mr. R. E. Prentice, Minister of State for Education and Science, assisted by Dr. Deacon and by Prof. M. J. Lighthill, the ehairman of the Oceanography and Fisheries Committee of the Natural Einvironment Research Council. Awareness on the part of the public was reflected in the emphasis which many of the exhibits placed on the user, particularly one showing over 120 enquiries from civil engineers, port authorities, etc., who have consulted the Institute in recent years for help about wave conditions and who noed advice, data or instruments. Such knowledge of waves is essential to those who build and operate ships, design hovercraft, drill for oil, build ports and other coastal installations, and also to those who attempt to control coastal erosion. This display particularly illustrated the statement of the director, Dr. Deacon, that "The Institute's main purpose is to improve understanding of the basic physical, chemical and biological processes that govern all events in the ocean, and, while taking every opportunity to increase knowledge, to help as much as possible in applying it". For many years the wave group at the National Institute of Oceanography has been recognized as second to none in the world both in. the study of the theory and statisties of waves and in the design of instruments for collecting measurements. The practical value of such academic research has become in.creasingly apparent to those who consult the National Institute of Oceanography. One major wave project in recent years has been the design of a series of buoys to measure the direction in which waves are travelling, the most recent dosign being a cloverleaf buoy which measures the pitch and roll of three floats held at the corners of an equilateral triangle. The direction of alignment of the buoy and the vertical acceleration at the centre of the triangle are also measured. The buoy and the ship are linked by a 26-core cable for carrying electrical power to the buoy and for bringing back reference signals and outputs to a multichannel recorder and data logger. From these records the directional spectrum of the sea waves can be computed. These results are of importance. both to wave theoreticians and to the British Ship Research Association for ship motion studies. That pure research can result in wave forecasting which may save a ship time in crossing the Atlantic, or otherwise improve its efficiency, is a vindication of the purpose of the Institute in studying fundamental problems of the ocean.

Another basic problem is the study of deep circulation of the ocean, with its concomitant idea of the transfer of energy from one part of the ocean to another. Since their development at this Institute ten years ago, neutrally buoyant floats have been used to measure currents at great depths in the sea and have radically changed our ideas about the movement of the deep water. The deep currents have been found to be faster and more variable than had been supposed-fast enough to have practical implications for problems of waste disposal in the deep sea and for the design of deep moorings. These variable currents may play an important part in the goneral circulation of the ocean, similar to that of depressions and waves in the atmospheric circulation. One display representing examples of the deep current observations in the North Atlantic Ocean showed a fast southflowing current close to the continental slope off North America. In mid-ocean, average speeds of $10 \mathrm{~cm} / \mathrm{sec}$ at great depths were found and there was evidonce of eddies some $100 \mathrm{~km}$ across. A narrow streak of water was discovered travelling at nearly 1 knot at $4,000 \mathrm{~m}$. It also appeared that the currents at such a depth were faster than those at mid-depth $(2,000 \mathrm{~m})$ and moved in a more nearly meridional direction.

Much of the information about deep-water masses and their movements is obtained by the classical and still essential method of making observations at hydrographic stations, samples of water being collected at various depths with simultaneous temperature recordings, and this was part of the required international survey of the physical oceanography of the Indian Ocean. A part of the hydrographic work of the third cruise of the R.R.S. Discovery in 1964 during the International Indian Ocean Expedition was shown by a display of sections of salinity, oxygen and temperature at different seasons along $58^{\circ} \mathbf{E}$. Besides the usual water-sampling and net hauls on stations in the Indian Ocean, relative currents were measured using propeller-type current meters in the near-surface water. Two of the most striking features were the equatorial undercurrent and the Somali current, which were both particularly well developed at the time they were investigated.

Another phenomenon associated with the Somali current, recorded as flowing north-east at nearly 7 knots, was the exceptionally cold coastal water. The association of recently dead fish with this upwelling was remarked on in the display of the Institute's biological section as was the upwelling from a different cause off the Arabian coast, investigated particularly in its association with the return of nutrients from the deep water to the surface. This was one aspect of a prominent part of the biological research, the investigation of the fertility of the oceans. Aspects of the organic cycle investigated at the Institute include photosynthesis, the growth of phytoplankton and its dependence on nutrients and chlorophyll, and the taxonomy and distribution of zooplankton, which has been investigated mainly by sampling and recently by echo-sounding. The R.R.S. Discovery, the main tool of the Institute, is at present at sea in the North Atlantic on a biological cruise, co-operating with visiting scientists from the United States, in an attempt to use underwater sound as a method to study the distribution of marine animals. At all times from the period of the Discovery Investigations to the present some members of the biological group have investigated certain animals in detail, most notably the common food of Antarctic 
whales, Euphausia superba, which was the work of tho late J. W. S. Marr. One of the most active investigations to-day is that of the squid, known as the diet of sperm whales, but also one of the most numcrous and widely distributed animal groups in the sea. The Whale Roscarch Unit showed exhibits representing its work with the biology of the larger species of whale of commercial importance, the bluo, fin, soi ard himpback whales and the sperm whale; as in the days of the Liscovery Investigations the immediate purpose is to provide scientific information to holp in the regulation of tho whaling industry, but in the long run to aid the conservation of whales. Most of the work of the Whalo Researeh Unit is therefore concornod with the distribution and migration, breeding cyoles, feeding and population structures of these large species of whalcs.

Associated with the hydrographical and biological work is the work of the chemists (the 306 hydrographic stations on the third cruise of the R.R.S. Discovery resulted in about 8,000 water samples on which somo 27,000 analyses were made while at soa). On show at the Institute were two particular projects in chemical oceanography, one concorned with a study of the major constituents and nutrients in sea-water, and the other concerned with certain related physical properties, such as electrical conductivity and density.

The three-dimensional and time-varying complexity of the ocean might make investigation of the sea-floor seem comparatively straightforward, but time variations can occur there as woll. One exhibit showed that skilled interpretation of sonar records can indicate the transport path of sediments on tho continental sholf in waters around the British Isles. Another exhibit of a detailed investigation of a part of the deop soa-floor showed how a turbidity ourrent, formod from land-dorived material accumulating on tho edge of the continental shelf and precipitated by some catastrophe down the continental slope, may have levelled out an abyssal platin by doposition of sediments in the Bay of Biscay and then erodod a connecting channol to a lower abyssal plain west of Portugal. Such dynamic sea-floor studies are unusual, the greater part of the work being on relatively stationary features now known from the painstaking accumulation of echo-sounding records (involving the design at this Institute of a deep sea 'precision' echo-soundor with an accuracy of 1 fathom in 3,000 fathoms) together with photographs of the deep sea-floor made with a National Institute of Oceanography undorwater camcra. Theso show such various pheromena as long ripples formed by bottom currents, boulders covered by a coating rich in manganese, steep slopes in charuncls and on sea mounts and possible basaltic lavas from the Mid-Atlantic ridge. Cores are obtained from both the deop and shallow setfloors, and further geological information on faults, folding and possible lithological structure of the sea-bed in shallow waters is obtained from the interpretation of sonar records. (It is evident that this shallow-water geology is of interest to exploratory oil companies.) One of the projocts recently started at this Institute is the development of a geological long-range sonar for use in deep water.

The National Institute of Oceanography took an active part in the sea-floor studies of the Interrational Indian Ocean Expedition. On all three eruises a continuous echo-sounding record was obtained; the second cruise was particularly concerned with the geophysics of the sea-floor and has helped to answer questions nbout the formation of mid-ocean ridges and their relation to continental drift. One exhibit showed tho possible development of the Gulf of Aden as a rosult of the splitting away of tho Arabian Peninsula from the African onntinent some 20 million years ago. In a senso, tho Indian Ocean work was a profitable digression from the work in the Atlantic. A contoured bathymetric chart of the north-onst Atlantic compiled from soundings collected in the Hydrographic
Department of the Navy (many of them taken by the R.R.S. Discovery II and the R.R.S. Discovery) showed clearly the structure of the Mid-Atlantic ridge and its median valley, the complexity of the continental shelf, and the recently explored deeps in a line with, and some four hundred miles west of, the north coast of Spain. This chart also amply demonstrates how it might profitably be used for navigation in conjunction with a precision echo-sounder. In itself, as it now stands, it could be of considerable use, involving possibly large financial savings, to those who lay cables across the soa-floor.

Much of the work at the National Institute of Oceanography is unique, particularly the electronic analogue model of the North Sea, which takes into account such variables as the topography of the sea-floor and the wind pattern, and which can predict storm surges with a reliability depending on the accuracy of the weather forecast. This is but one more instance of what was very evident in most of the exhibits, the application to-day of work which some years ago wes of academic interest only.

Many of the exhibits showed that, as yet, many projects are necessarily incomplete; much of the work is as yet unpublished; the gear is constantly being improved; the data obtained, despite the use of computers, prove all but intractable in quantity to the very few scientists who wish to use them, and who are yet aware that these very observations are pitifully few in relation to the size of the ocean. The most urgent need is for more people to tackle the present problems, let alone those problems which will become apparent as more gradually becomes known about the ocean. Necessarily, most of the exhibits showed the work of the past 16 years, but some included indications of that planned or hoped for in the future, such as the thermistor chain, an instrument which should be particularly useful for moasuring internal waves from ships underway at speeds up to 12 knots, and depths up to $2,000 \mathrm{ft}$. The temperature-sensing units will be towed at $50 \mathrm{ft}$. or $100 \mathrm{ft}$. intervals on a single-core doublearmoured cable. It is hoped also to do more work on the results of the two seismograph stations, one st Wormley and one at Haslemere, and by analysing the six outputs from these stations, to obtain the two-dimensional spectrum of microseisms at any instant of time; this will give information as to the direction of arrival of the microseisms. Their relationship to sea-waves generated in storm centres has already been clearly demonstrated. More information, too, can be obtained from the pressure telemeter designed for use on the edge of the continental shelf, this instrument having been planned to measure the very small pressure fluctuations on the ocean floor caused by the passage of surface waves overhead.

Other exhibits, more complete in themselves and distinot in their applications, ranged from the simple devices (such as jelly bottles for mossuring currents, especially at the bottom, which are of particular interest to fishormen and civil engineers) to the sophistication of 'vorticity waves'. It is suggested by theory that if a mass of fluid such as the sea, or atmosphere is rotating nearly uniformly an unusual type of wave motion can be projected through the fluid. A model was demonstrated showing such vorticity waves set up in water in a rotating cylindrical vessel.

When the Royal Charter was granted in 1950 there were thirteen listed objects for which the Council was established and incorporated; the first, and necessarily foremost, of these was "to advance the science of oceanography in all its aspects", and the engineering section of the Institute, in addition to designing and making the prototypes of almost all the instruments used at the Institute, both in the laboratory and at sea, has provided instruments and equipment to other laboratories throughout the world. Much of the gear is required in too small numbers to be produced commercially and in addition there is already in the Institute an accumulated knowledge of the diffioul. tios caused by high pressure at great depths in the ocean 
and by the corrosive properties of sea-water. About forty projects were displayed as exhibits by the engineering section both as instruments and by working drawings, out of some 120 designed in the past sixteen years. Some of the more recent instruments have been briefly referred to here. The stabilized narrow-beam transducer is at present being used in the R.R.S. Discovery; this is part of a $36-\mathrm{kc} / \mathrm{s}$ underwater acoustic echo-ranger used for work on fish-detertion problems and marine geological investigations. The axis of the acoustic beam is perpendicular to the fore-and-aft line of the ship and may be rotated from the horizontal to the downward vertical. Gyro istabilization is provided against the roll of the ship; beam width and side lobe patterns are adjustable. The range is about $800 \mathrm{yd}$. and scanning is achieved by steering the ship past the features to be investigated. A more recent project is the towed vehiele, which houses a transducer array for the long-range geological slanting sonar briefly mentioned here as being intended for use in deep water, which will work at a much lower frequency and will necessarily be largor than the sonar used in shallow water. It is intended that the vehicle will bo towed at a depth of about $400 \mathrm{ft}$. and, in order to obtain adequate signal levels for the sound seattered back by the sea-floor, each of the 144 transducer elements will transmit $400 \mathrm{~W}$ of acoustic power. In connexion with the thermistor chain a helical traversing capstan is being developed as the traction member of a deep-sea hoist for handling faired electric cables. The capstan is so constructed that the cable advances across its surface with a purely rolling action, free of slipping or sideplay; there are no unbalanced forces to cause the path to be altered.

Yet another stated object of the Royal Charter was to collect and maintain an oceanographic library and, starting in 1953 with the welcome nuclei of earlier collections, the National Institute of Oceanography Library has now grown to be one of the major oceanographic libraries, containing about 3,500 text-books, 25,000 reprints and 7,000 unpublished reports all cross-indexed for easy reference, together with an annual intake of about 400 periodicals. There is a specialized collection of charts and atlases and a fine collection of seientific reports of oceanographic expeditions. The publications of the Institute, the Collected Reprints and Discovery Reports, are distributed on a world-wide basis, preferably with an exchange arrangement. In a year the library lends some 3,000 publications, about 2,500 to scientists at the Institute and the othors to many outside libraries.

The work of the Institute over the past 16 years was ropresented by these exhibits; the general line for the future was discussed at the press conference. It was reassuring to hear from Mr. Prentice that both the growth and continuity of the present work of the Institute would be maintained under the Natural Environment Research Council and encouraging to hear Prof. Lighthill comment on the fact that, although little money had been spent on the National Institute of Oceanography, yet the return had been good value; the amount of money spent on researeh is not necessarily in direct proportion to the results.

\section{INSECT BEHAVIOUR}

$\mathrm{T}$ HE Royt Entomological Society of London continued its series of biennial symposia by organizing a meeting on "Insect Behaviour" which was held at the Imperial College of Science and Technology, London, during September 23-24, 1965. The meeting was oponed by Mr. F. O. Pearson, the president of the Society, who pointed out that the objective of this series of symposia was to provide authoritative surveys of recent work in the chosen field for the information of entomologists generally, and the very high attendanee at this meeting emphasized that these symposia fulfil a real need.

Prof. Birukow (Göttingen) spoke on orientation behaviour and factors which influence it. This particular aspect of insect behaviour is engaging the attention of several German entomologists, and Prof. Birukow was able to indicate the way in which past attempts at the systematization of the subject contrasted with more recent approaches such as those of Jander. $\mathrm{He}_{\theta}$ described the eapacities and physiological mochanisms of lower levels of orientation behaviour (the so-ealled baso-taxes) and pointed out that higher orientation behaviour may have evolved from these. The variability noted in orientation behaviour results principally from adaptive variability which ensures that an animal can nover become 'a slave to its own orientation mechanisms'. Insect orientation behaviour cen bo adjusted by the interaction of innate and learned patterns, but in complex behaviour it is rarely possible to discriminate between these two sources. Prof. Birukow gave details of his interesting work on light orientation in Calandra granaria, which is affected by biological rhythms and meteorological factors.

Dr. P. S. Corbet (Ottawa) gave an account of the role of rhythms in insect behaviour, and from this wide ficld took as his main thome the factors which influence field periodicities. Particularly valuable were his clear definitions of the terms used to describe periodic behaviour and his elucidation of the relationships between them. $\mathrm{He}$ pointed out that the causal analysis of field periodicities in terms of their endogenous and exogenous components had been neglected because integration of field and laboratory work on periodic behaviour had seldom been attempted. He underlined the need for investigations of the poriodicity of single processes in the laboratory under controlled conditions and also in Nature, preferably in several situations. $\mathrm{He}$ particularly emphasized the need for entomologists to recognize the pervasiveness of rhythmicity as an experimental variable. He instanced the response to sex pheromones, the amount of body protein and the intensity of virus transmission as processes under control of circadian rhythms which, therefore, show different values at different times of day and night. He suggested that a description of any such process should properly include an account of its periodicity, particularly when this affects its measurement or detection.

Dr. P. T. Haskell (London) discussed flight behaviour, first mentioning factors inhibiting or limitirg to insect flight, particularly the effect of wind on height of flight and orientation. He went on to outline the general aspects of flight behaviour in respect of food-seeking, homing and territorial flight, defence and predator avoidance, courtship and mating, oviposition and migration and dispersal. He pointed out that there seem to be certain basic patterns which are utilized in different types of behaviour such as, for example, food-seeking and oviposition, which pose the same fundamental problem to the insect, that of homing on a target. He described recent work on mechanisms involved in anemotactic behaviour released by olfactory stimuli, which are important in relation to mating, food and oviposition behaviour, and queried theoretical deductions which supposedly rule out tropotactic orientation to an odour source.

Prof. V. G. Dethier (Pennsylvania) dealt with feeding behaviour and pointed out that in the past decades the emphasis in this field of investigation had altered from description to an investigation of mechanisms. $\mathrm{He}$ examined the present-day controversies as to whether 